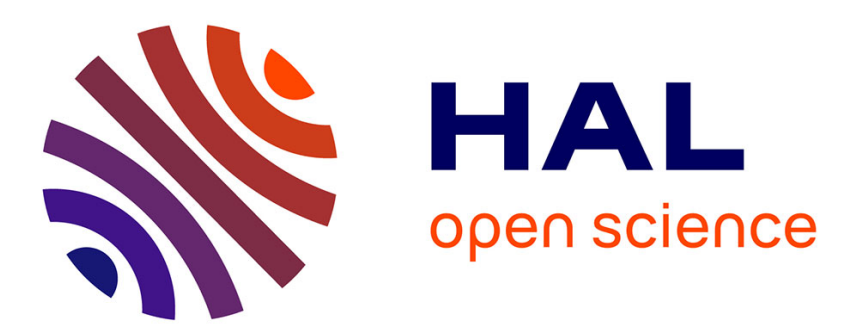

\title{
Optimization of the Deposition Conditions of Titanium Nitride from Ammonia and Titanium Tetrachloride
}

\author{
M. Nadal, F. Teyssandier
}

\section{To cite this version:}

M. Nadal, F. Teyssandier. Optimization of the Deposition Conditions of Titanium Nitride from Ammonia and Titanium Tetrachloride. Journal de Physique IV Proceedings, 1995, 05 (C5), pp.C5809-C5-814. 10.1051/jphyscol:1995596 . jpa-00253959

\section{HAL Id: jpa-00253959 https://hal.science/jpa-00253959}

Submitted on 1 Jan 1995

HAL is a multi-disciplinary open access archive for the deposit and dissemination of scientific research documents, whether they are published or not. The documents may come from teaching and research institutions in France or abroad, or from public or private research centers.
L'archive ouverte pluridisciplinaire HAL, est destinée au dépôt et à la diffusion de documents scientifiques de niveau recherche, publiés ou non, émanant des établissements d'enseignement et de recherche français ou étrangers, des laboratoires publics ou privés. 


\title{
Optimization of the Deposition Conditions of Titanium Nitride from Ammonia and Titanium Tetrachloride
}

\author{
M. Nadal and F. Teyssandier \\ Institut de Science et de Génie des Matériaux et Procédés, UPR 8521 du CNRS, Université, Av. de \\ Villeneuve, 66860 Perpignan cedex, France
}

\begin{abstract}
TiN has been used in numerous technological applications including: cutting or milling tools and inserts, cold extrusion nozzles and punches, forming or stamping tools, and diffusion barrier. It is currently deposited from an initial gas mixture composed of hydrogen, ammonia and titanium tetrachloride. This paper reports on the optimization of its deposition conditions at atmospheric pressure. A complete factorial design with three factors and two levels, thus requiring $2^{3}=8$ experiments, has been carried out. The following parameters were selected: the deposition temperature, the molar fraction of titanium tetrachloride and the molar fraction of ammonia. The influence of these factors on the deposition rate, the grain size estimated by the Scherrer method and the texture coefficient as determined by X-ray diffraction were studied. The mechanical properties of the coatings (microhardness, Young's modulus) were measured by depth-sensing indentation.
\end{abstract}

\section{INTRODUCTION}

Owing to both its attractive gold color and its mechanical properties (hardness, wear resistance, friction coefficient), titanium nitride has been used in numerous technological applications such as cutting or milling tools and inserts or diffusion barrier [1]. Traditionally, these substrates have been industrially coated from an initial gas mixture composed of hydrogen, nitrogen and titanium tetrachloride. Due to the high thermal stability of these compounds, a high deposition temperature is required $\left(800^{\circ} \mathrm{C}\right)$. Such a high temperature maintained throughout the process enhances solid state reactions between the film and the substrate, increases residual stresses due to thermal expansion mismatch between the substrate and coating and promotes grain growth in the substrate structure. In order to minimize these problems it is helpful to deposit the coatings at a lower temperature. This can be achieved by conventional thermal CVD using less stable molecules such as organometallic compounds or ammonia for the nitrogen precursor.

The TiCl4 $-\mathrm{NH}_{3}-\mathrm{H}_{2}$ mixture has been used by several authors to deposit at low temperature TiN films either for thermomechanical applications [2-4] or as diffusion barrier [5-8].

This paper is intended to optimize the deposition conditions of titanium nitride films on molybdenum substrate from a titanium tetrachloride, ammonia, nitrogen and hydrogen gas mixture. Equiaxed materials with small grain size and a high deposition rate were the criteria selected for the optimization procedure.

\section{EXPERIMENTAL DETAILS}

\subsection{Film characterization}

Scanning electron micrographs (SEM) were obtained on a Hitachi S520 Electron Microscope, equipped with an Energy Dispersive Spectrometer (EDS), Tracor 5500. X-ray diffraction studies were conducted using a Philips PW 1729 X-ray diffractometer with a copper anticathod.

- The grain size was estimated from X-ray diffraction analysis by the Scherrer method [9]:

For grain sizes ranging from 20 to $3000 \AA$ :

$$
D=\frac{k \lambda}{\beta \cos \theta}
$$


with $\lambda$ anticathod wavelength ( $1.5418 \AA \mathrm{Cu}$ ), $\theta$ Bragg angle, $\mathrm{k}$ constant close to one (for $B$ in radian unit). $A$ value of $k=0.9$ is usually chosen for spherical particles with homogeneous size distribution. $B^{2}=B_{o}^{2}-b^{2}$

$B$ is the pure breadth of a powder reflection free of all broadening due to the experimental method employed in observing it.

$B_{O}$ broadening resulting from the grain size at $2 \theta$, b other broadening factors such as apparatus factor .

The influence of the experimental method (b) was estimated by the broadening of peaks of a highly crystallised titanium carbide coating deposited at high temperature and thus presenting large grain sizes.

- The preferential orientation of the deposits was determined from X-ray diffraction analysis and quantified by the following texture coefficient [9] :

$$
\mathrm{TC}_{\mathrm{hkl}}=\frac{\frac{\mathrm{I}_{\mathrm{hkl}}}{\mathrm{I}_{\mathrm{hkl}}^{0}}}{\frac{1}{\mathrm{n}} \sum_{1}^{\mathrm{n}} \frac{\mathrm{I}_{\mathrm{hkl}}}{\mathrm{I}_{\mathrm{hkl}}^{0}}}
$$

where $I_{h k l}$ is the intensity of reflection from a given set of plane $\{h k l\}, I_{h k l}^{0}$ is the intensity from the same set of plane $\{\mathrm{hkl}\}$ for a random sample such as the powder spectrum of titanium nitride (JCPDS reference $\mathrm{n}^{\circ} 38-1420$ ) and $\mathrm{n}$ is the number of reflections that were considered.

- The thickness of the deposits was determined by abrasion through the coating, obtained by the rotation of a $15 \mathrm{~mm}$ diameter stainless steel ball together with an abrasive agent ( 1 or $3 \mu \mathrm{m}$ diamond). The thickness was calculated from the diameters of the ring prints measured by optical microscopy or by SEM for ring print diameter larger than $1 \mathrm{~mm}$.

- The atomic compositions of the coatings were determined from electron probe microanalysis with wavelength dispersive spectroscopy (EPMA-WDS, Camebax, at $15 \mathrm{kV}$ excitation voltage using the PAP correction program) performed on metallographic preparations of cross-sections. The standards were pure and stoichiometric $\mathrm{TiC}$ for titanium, $\mathrm{Fe}_{2} \mathrm{O}_{3}$ for oxygen and $\mathrm{NaCl}$ for chlorine. However, due to the overlapping of the $\mathrm{L} 1$ titanium peak and $\mathrm{K} \alpha$ nitrogen peak the nitrogen content could not be measured and was thus estimated by difference with the concentration of other elements.

\subsection{CVD configuration and procedure}

Deposition of TiN was performed in a vertical hot-wall reactor operating at atmospheric pressure (figure 1).

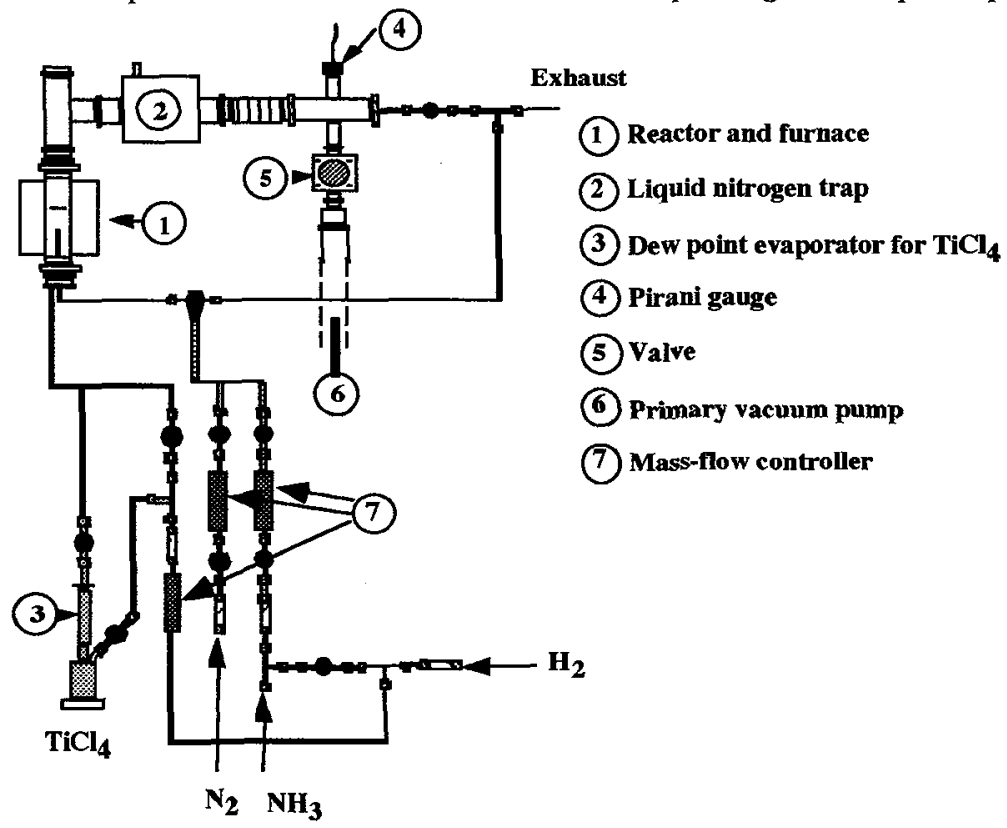

Figure 1: Schematic of the experimental device. 
The partial pressure of titanium tetrachloride was imposed through a dew point evaporator and with hydrogen as carrier gas $(30 \mathrm{sccm})$. In order to prevent the formation of solid particles, the titanium tetrachloride and ammonia flows were mixed inside the reactor by two concentric inlets at a position corresponding to a gas temperature of about $573 \mathrm{~K}$. Due to the low ammonia flow rate, a $30 \mathrm{sccm}$ flow of nitrogen was added. The molybdenum substrates were polished using $1 \mu \mathrm{m}$ diamond paste. The hydrogen, nitrogen and ammonia flow rates were controlled with mass-flow controllers. Before each experiment, the CVD system, loaded with the substrate, was evacuated for $8 \mathrm{~h}$ and purged with hydrogen for 30 min (1 $\operatorname{sim})$. At the end of each experiment, heating of the crucible was stopped, and the temperature of the substrate was decreased gradually, with the hydrogen flow rate maintained until the substrate had reached room temperature.

\section{RESULTS OF THE EXPERIMENTAL DESIGN}

An experimental design was worked out to determine the influence of three main factors. A complete factorial design with three factors and two levels, thus requiring $2^{3}=8$ experiments, was then carried Among the numerous factors that may have significant influence on the deposition process, the temperature of the substrate, the titanium tetrachloride and ammonia partial pressures in the initial gas mixture were selected according to previous results. The variation ranges of selected factors, which are defined by the lower and higher levels of the experimental design, are summarised in Table 1.

Table 1: levels of the three factors used in the experimental design. Other parameters were constant: $P=1$ atm, hydrogen flow rate $500 \mathrm{sccm}$, nitrogen flow rate $500 \mathrm{sccm}$, deposition time $60 \mathrm{~min}$.

\begin{tabular}{|c|c|c|c|}
\hline & $\begin{array}{c}\text { Substrate temperature } \\
(\mathrm{K})\end{array}$ & $\begin{array}{c}\text { TiCl4 flow rate } \\
(\mathrm{sccm})\end{array}$ & $\begin{array}{c}\text { Ammonia flow rate } \\
(\mathrm{sccm})\end{array}$ \\
\hline level + & 973 & 3.0 & 3.3 \\
\hline level - & 873 & 1.6 & 1.6 \\
\hline
\end{tabular}

Three responses, (thickness of deposit, grain size, texture coefficient) were studied. All the results are presented in Table 2 . The following amount of contamination elements were measured by EPMA-WDS: $\mathrm{C}=1$ at $\%, \mathrm{Cl}=1$ at $\%, \mathrm{O}=4$ at $\%$

Table 2: results of the experimental design.

\begin{tabular}{|c|c|c|c|c|c|c|c|c|}
\hline Sample & $\mathrm{TiCl}_{4}$ & $\mathrm{~T}$ & $\mathrm{NH}_{3}$ & $\begin{array}{l}\text { Coating } \\
\text { thickness } \\
(\mu \mathrm{m})\end{array}$ & $\begin{array}{c}\text { Grain } \\
\text { size } \\
\AA\end{array}$ & $\mathrm{TC}_{111}$ & $\mathrm{TC}_{200}$ & $\mathrm{TC}_{220}$ \\
\hline 1 & - & - & - & 2.0 & 569 & 0.71 & 1.58 & 0.72 \\
\hline 2 & - & - & + & 4.0 & 158 & 0.62 & 1.70 & 0.69 \\
\hline 5 & - & + & + & 4.0 & 569 & 0.29 & 2.49 & 0.22 \\
\hline 7 & - & + & - & 2.5 & 452 & 0.80 & 1.63 & 0.57 \\
\hline 8 & + & - & - & 2.5 & 118 & 0.64 & 2.01 & 0.34 \\
\hline 9 & + & - & + & 6.8 & 333 & 0.27 & 2.44 & 0.29 \\
\hline 10 & + & + & + & 7.0 & 333 & 0.96 & 1.16 & 0.88 \\
\hline 11 & + & + & - & 3.2 & 297 & 0.93 & 1.46 & 0.61 \\
\hline
\end{tabular}


From an examination of Table 2 , it is immediately obvious that sample 10 corresponding to $\mathrm{TiCl}_{4}=3.0$ sccm, $\mathrm{NH}_{3}=3.3 \mathrm{sccm}$ and $\mathrm{T}=973 \mathrm{~K}$ yields almost optimized results according to the criteria previously mentioned. As a matter of fact, these conditions provide the highest deposition rate as well as almost equiaxed TiN coatings.

When a restricled number of factors are considered, a response surface, which is the description of experimental results by a polynomial expression, can be determined by a multiple regression technique [10]. The following polynomial expressions were determined to represent the variations of the layer thickness and the variation of the grain size within the experimental domain:

Thickness $(\mu \mathrm{m})=4+\mathrm{TiCl}_{4}^{*} 0.875+\mathrm{T}^{*} 0.175+\mathrm{NH}_{3}^{*} 1.45+\mathrm{TiCl}_{4} \cdot \mathrm{T}^{*} 0.05-\mathrm{T} . \mathrm{NH}_{3}{ }^{*} 0.125+$ $\mathrm{TiCl}_{4} \cdot \mathrm{NH}_{3} * 0.575+\mathrm{TiCl}_{4} \cdot \mathrm{T} . \mathrm{NH}_{3} * 0.0$

Grain size $(\AA)=354-\mathrm{TiCl}_{4} * 83.4+\mathrm{T} * 59.1-\mathrm{NH}_{3}^{*} 5.4-\mathrm{TiCl}_{4} \cdot \mathrm{T}^{*} 14.4+\mathrm{T} . \mathrm{NH}_{3} * 43.6+$ $\mathrm{TiCl}_{4} \cdot \mathrm{NH}_{3} * 68.1-\mathrm{TiCl}_{4}$. T. $\mathrm{NH}_{3} * 88.4$

The comparison between the deposit thickness variation plotted as a function of the titanium tetrachloride and ammonia flow rates for the two deposition temperatures in figure 2 clearly shows that the temperature range investigated in the experimental design is not significant for this response. This suggests that, in spite of the relatively low temperature range of deposition investigated, the deposition rate is already controlled by the mass transfer in the gas phase. These variations furthermore reveal the strong positive influence of the ammonia flow rate on the deposition rate. The same influence is observed for the titanium tetrachloride flow rate but to a less extent. In particular, a coupling effect between these two parameters is responsible for an almost complete lack of influence of the titanium tetrachloride flow rate at low ammonia flow rate. For these deposition conditions, this result is indicative of a control of the deposition mechanism by the mass transfer of ammonia towards the surface which is strongly dependent on its content in the initial gas mixture.

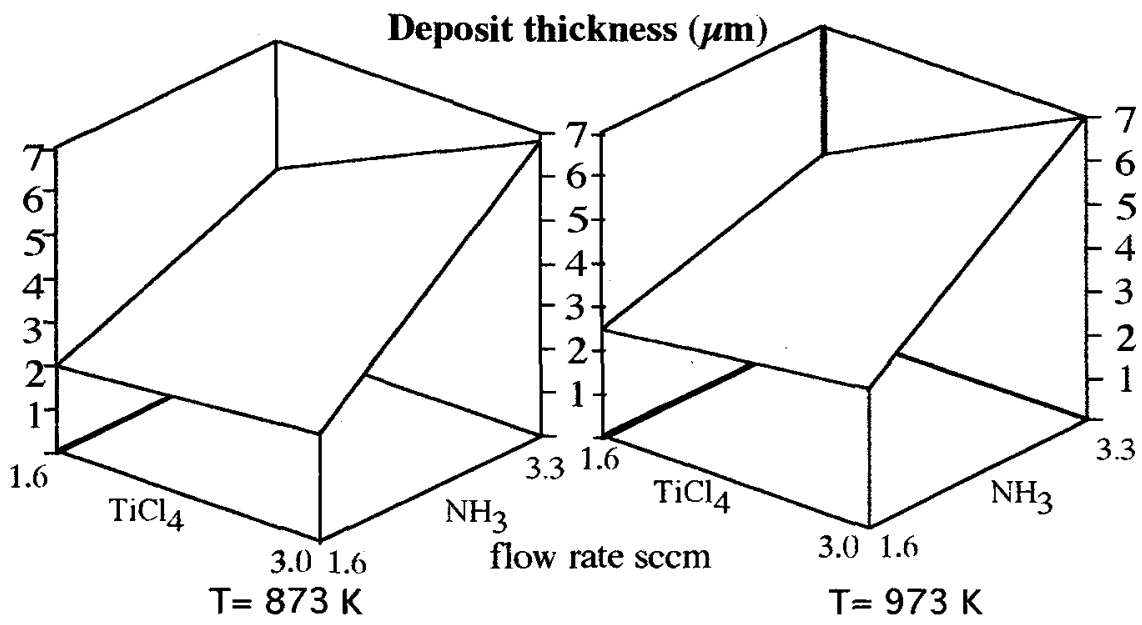

Figure 2: Variation of the deposit thicknesses as a function of the titanium tetrachloride and ammonia flow rates for the two deposition temperatures.

The variation of the grain size is plotled as a function of the titanium tetrachloride and ammonia flow rates for the two deposition temperatures in figure 3. In the CVD process two main parameters are mainly influential on the grain size: the deposition temperature and the supersaturation of the gas phase. In our case, the grain size increases with temperature as usually observed according to the increased mobility of atoms at the surface. Due to the restricted range of temperature which was investigated, this influence is rather limited and furthermore dependent on the composition of initial gas phase. The already mentioned control of the deposition rate by the mass transfer in the gas phase usually results in a low supersaturation of the reactant species at the interface with the substrate. Accordingly, a weak influence of the composition of the initial gas phase on the grain size is expected. At $973 \mathrm{~K}$, as a general trend, the grain size is 
increasing with the $\mathrm{NH}_{3}$ content and with a decrease of the $\mathrm{TiCl}_{4}$ content, but this feature is no longer observed at $873 \mathrm{~K}$.

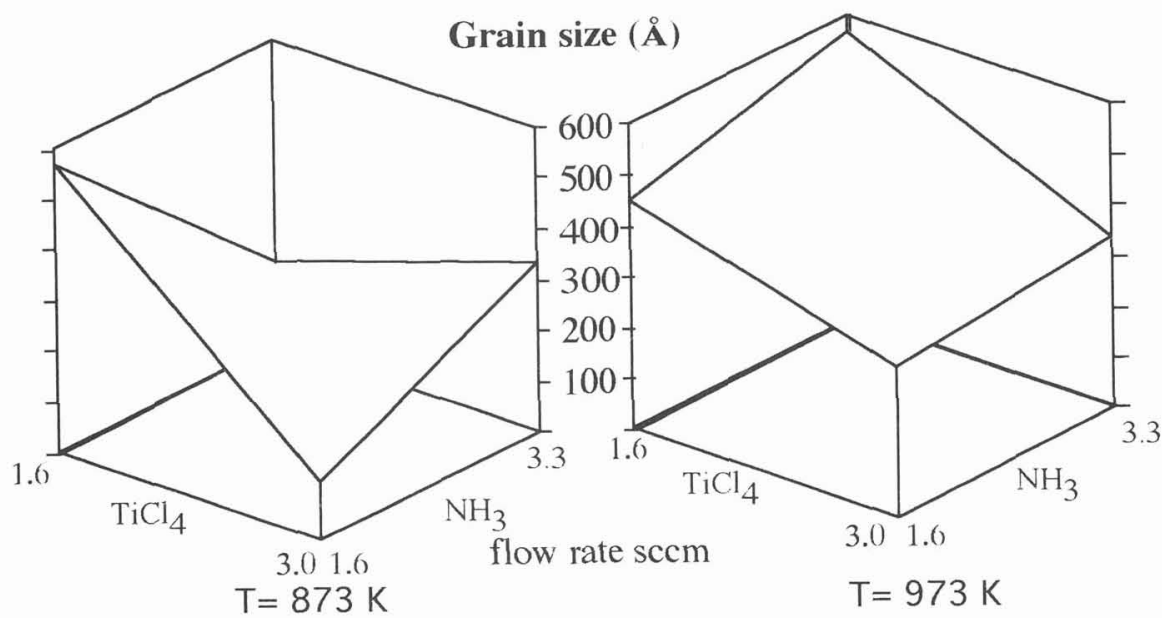

Figure 3: Variation of the grain size as a function of the titanium tetrachloride and ammonia flow rates for the two deposition temperatures.

Hardness and Young's modulus were measured by a depth-sensing indentation instrument (Nano-indenter II, Nanoinstruments). This mechanical microprobe provides a continuous load-displacement recording in an ultra-low load range of investigation. The Berkovich type indenter is a diamond tip with a three-sided pyramid shape and an apex angle of $65.3^{\circ}$. The indentation depth ranged between 300 and $400 \mathrm{~nm}$ for a maximum load of $50 \mathrm{mN}$. Typical load and displacement resolutions were respectively $0.075 \mu \mathrm{N}$ and 0.04 $\mathrm{nm}$. Five indents were performed on polished cross-sections (figure 4).

A typical indentation cycle corresponding to sample 10 is presented in figure 5. For all the tested coatings the hardness ranged from 21 ko 22 GPa. Such a value is typical of crystallized titanium nitride materials. A Young's modulus of $445 \mathrm{GPa}$ was measured on sample 10 whereas lower values in the range 325 to 340 GPa were obtained on other coatings. These values are also characteristic of titanium nitride, and these variations can result from varying residual porosities as observed in figure 4 . As a comparison, the hardness and Young's modulus values measured on a titanium nitride deposited by CVD at high temperature and thus presenting larger grain size, were respectively of $21 \mathrm{GPa}$ and $437 \mathrm{GPa}$.

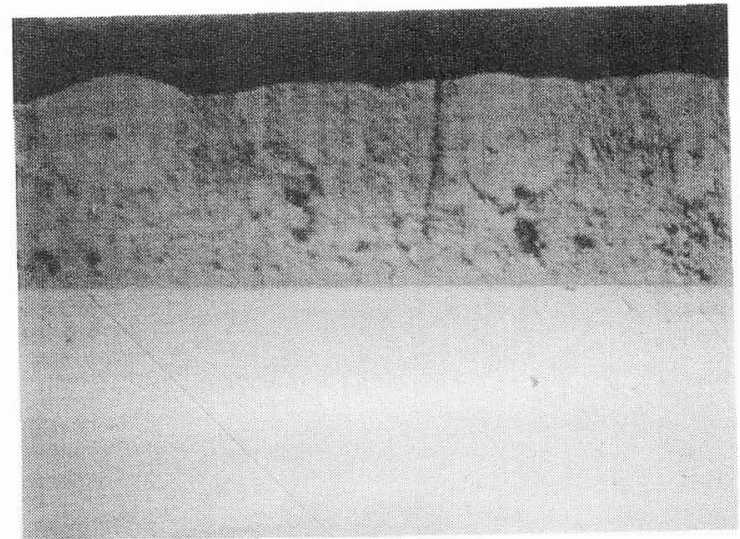

Figure 4: SLM photograph of the polished cross-section of sample 10. 


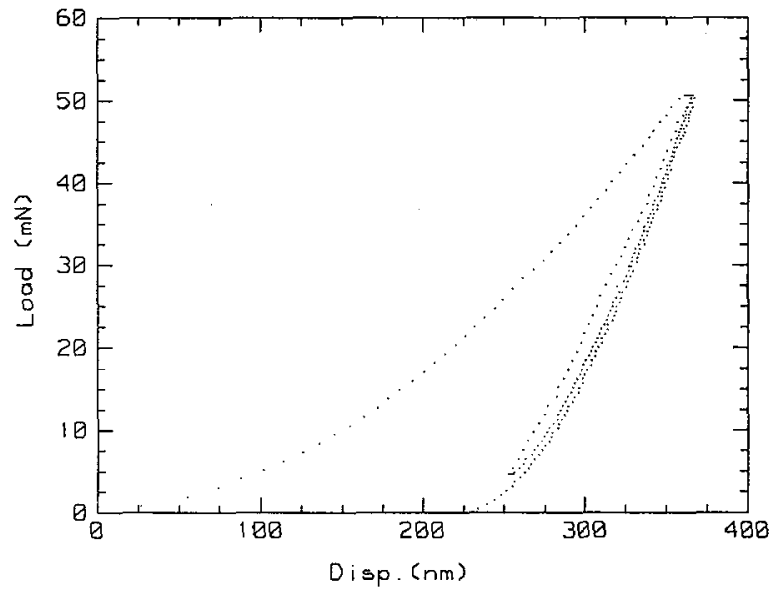

Figure 5: typical indentation cycle revealing the elasto-plastic behavior of titanium nitride.

\section{CONCLUSION}

A complete factorial design with three factors and two levels has been carried out in order to optimize the deposition conditions of titanium nitride films on molybdenum substrate. A set of deposition conditions $\left(\mathrm{TiCl}_{4}=3.0 \mathrm{sccm}, \mathrm{NH}_{3}=3.3 \mathrm{sccm}\right.$ and $\mathrm{T}=973 \mathrm{~K}$ ) was determined to provide coatings that met almost all the prerequisite criteria: equiaxed materials with small grain size and a high deposition rate. In spite of the relatively low temperature range of deposition investigated, the deposition rate was controlled by the mass transfer in the gas phase, and especially by the mass transfer of ammonia towards the surface. The grain size increased with temperature, but the influence of the gas phase composition on this response was not straightforward. The hardness and Young's modulus as measured by a depth-sensing indentation instrument were typical of crystallized titanium nitride materials.

\section{References}

[1] Rebenne H.E. and Bhat D.G., Surf.Coat.Technol., 63 (1994) 1-13.

[2] Sjostrand M.E., "Deposition of wear resistant TiN on cemented carbides using mixtures of $\mathrm{NH}_{3} / \mathrm{N}_{2}$ and $\mathrm{TiCl}_{4} / \mathrm{H}_{2}$." VII Intern. Conf. on $\mathrm{CVD}$, Los Angeles USA, 1979, Sedgwick T.O., Lydtin H. Eds, (The Electrochemical Society, 1979), pp. 452-462.

[3] Kurtz S.R. and Gordon R.G., Thin Solid Films, 140 (1986) 277-290.

[4] Jiang C., Goto T. and Hirai T., J.Mater.Sci., 29 (1994) 669-675.

[5] Sherman A., J.Electrochem.Soc., 137 (1990) 1892-1897.

[6] Yokoyama N., Hinode K. and Homma Y., J.Electrochem.Soc., 138 (1991) 190- 195.

[7] Buiting M.J. and Otterloo A.F., J.Electrochem.Soc., 139 (1992) 2580-2584.

[8] Kaizuka T., Shinriki H., Takeyasu N. and Ohta T., Jpn.J.Appl.Phys., 33 (1B) (1994) 470-474.

[9] Barrett C.S. and Massalski T.B., Structure of metals, (Pergamon Press, Oxford, First Edition, 1980)

[10]N.R.Draper and H. Smith, Applied Regression Analysis, Wiley, New York, 1966. 